\title{
One Point Fixation Versus Two Point Fixation in Zygomaticomaxillary Complex Fractures
}

\author{
Muhammad Husnain Akram ${ }^{1}$ \\ Muhammad Mustafa $\mathrm{Ch}^{2}$ \\ Armaghan Israr Mirza ${ }^{3}$ \\ Muhammad Usman Akhtar ${ }^{4}$ \\ Ammar Saeed $^{5}$
}

\author{
BDS, MFDRCSI \\ BDS, MDS \\ BDS, FCPS, FFDRCS \\ BDS, MCPS, MDS, BSc \\ BDS, FCPS
}

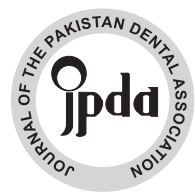

OBJECTIVE: To compare the mean satisfaction of patients undergoing one point fixation versus two point fixation for zygomaticomaxillary complex fractures.

METHODOLOGY: This randomized controlled trial was performed at Oral and Maxillofacial surgey department Punjab Dental Hospital. The duration of this study was 6 months (28-8-18 to 28-2-19). After meeting the inclusion criteria 74 patients were enrolled. Informed consent and demographic information was taken. Patients were randomly divided into two groups. One group is treated with one point fixation method and other with two point fixation. Patient were evaluated in terms of satisfaction of score on 3rd day, 14th day and 28th day and were recorded as per operational definitions. All the collected data was entered and analyzed on SPSS version 20.

RESULTS: In this study the mean age of patients in one point group was $42.46 \pm 15.325$ years while in two points group was $49.32 \pm 13.145$ years, male to female ratio of the patients was 1.2:1. The mean PSS in one point group was $5.98 \pm 0.89$ while in two points group was $3.775 \pm 0.609$ (p-value $=<0.001$ ).

CONCLUSION: One point fixation is smarter method and provide significantly better satisfaction than to two point fixation method for ZMC fractures

KEYWORDS: Zygomaticomaxillary Complex Fractures, One Point, Two Point, Satisfaction

HOW TO CITE: Akram MH, Ch MM, Mirza AI, Akhtar MU, Saeed A. One point fixation versus two point fixation in zygomaticomaxillary complex fractures. J Pak Dent Assoc 2021;30(2):74-80.

DOI: https://doi.org/10.25301/JPDA.302.74

Received: 16 September 2020, Accepted: 25 December 2020

\section{INTRODUCTION}

$\mathrm{T}$ he facial skeletal serves a key importance in human body. ${ }^{1}$ Apart from aesthetics, it gives sense of organ for smell, sight and taste. It also facilitates eating, chewing, breathing and speech .The facial bones share frontal bone, nasal bones, maxillae, zygoma and mandible. And the two maxillae form the middle third of facial skeleton and attached laterally with the two zygomatic bones at

1. FCPS Part-II Resident, Department of Oral and Maxillofacial Surgery, deMontmorency College of Dentistry, Punjab Dental Hospital Lahore.

2. Assistant Professor, Department of Oral and Maxillofacial Surgery Department, deMontmorency College of Dentistry, Punjab Dental Hospital Lahore.

3. Associate Professor, Department of Oral and Maxillofacial Surgery, King Edward Medical University Mayo Hospital Lahore.

4. Professor, Department of Oral and Maxillofacial Surgery, deMontmorency College of Dentistry, Punjab Dental Hospital Lahore.

5. Consultant, Department of Oral and Maxillofacial Surgery, deMontmorency College of Dentistry, Punjab Dental Hospital Lahore.

Corresponding author: "Dr. Muhammad Husnain Akram"

< husnainakram@hotmail.com > zygomaticomaxillary sutures. ${ }^{2}$

Zygomaticomaxillary complex (ZMC) is the skeletal unit of middle third of face. The boundary of the cheek is defined by zygoma and it separates orbit from maxillary antrum and infratemporal fossa.The zygomatic bone is a quadrangular-shaped bone. It articulates with the four bones at four sutures i.e frontal, temporal, maxillary and sphenoid bones. These sutures are usual weakness areas for fractures. ${ }^{2}$ The zygomatic bone fractures are the one of the most common mid-facial bone fracture. ${ }^{3}$

The commonest causes of ZMC fractures are RTAs, falls, violence, work and sports accidents, gunshot wound/blast injuries. Incidence of these fractures is more common among males than females with a 3-5:1 whereas in underdeveloped countries the ratio is as high as 10-40:12. These are most frequent among people who are aged 20-30 years. ${ }^{5}$

These fractures are diagnosed usually clinically, and 
confirmed by the radiographs like paranasal sinus (PNS) and occipitomental $(\mathrm{OM})$ views at different angles. In some cases specialized computerized tomography (C.T scan) is performed as per requirement. ${ }^{1}$

The treatment of zygomatic bone fracture is either by closed or open reduction. In closed reduction, various approaches like Gillies, Keens, Gerald screw, Champion's technique and Passwalo hook are used. ${ }^{6}$ These techniques have advantages and disadvantages on each other .In open reduction, the bone ends are surgically exposed and fracture site is fixed either by osteosynthesis or transosseous wiring after reduction of the fracture site. ${ }^{7}$

This purpose of this research is the comparison of one versus two point fixation to achieve better outcomes clinically such as patient satisfaction in terms of aesthetics consequently contributing towards the better treatment option for the benefit of patient. In one study conducted in South Korea, the satisfaction score for surgery was $9.4 \pm$ 1.6 in one point fixation group and $7.7 \pm 2.6$ in two point fixation group. ${ }^{2}$

Rationale is to find out the better treatment modality as limited number of local studies is available on this topic. There are more number of trauma cases in Pakistan as large number of population belongs to poor socio-economic status. The mode of transport for a large number of population in Pakistan is mainly motor bikes. Due to lack of awareness, majority of the people do not wear helmets for safety. As the number of trauma cases due to poor socio-economic status of majority of the population in Pakistan is larger, we want to identify a technique with more satisfaction score and more better outcomes so as to provide better treatment modality to patients. The technique which shows better results in future was preferred for public to provide maximum benefits to the patients in terms satisfaction considering the aesthetics.

\section{METHODOLOGY}

To compare the mean satisfaction of patients undergoing one versus two point fixation for ZMC fractures was the objective of this study. The study design is Randomized Control Trial. It was conducted in the in the setting of Oral \& Maxillofacial Surgery Department Punjab Dental Hospital. The duration was 6 months i.e. from 28-08-18 to 28-02-19. The sample size of this study is 74(37 in each group) and the technique which is followed is Non- Probability Consecutive Sampling. The inclusion criteria of this study includes i.e All patients presenting with zygomaticomaxillary complex fracture as confirmed with diagnostic imaging involving X-rays i.e. Occiptomental and Submentovertex views respectively and fulfilling other inclusion criterias were recruited in this study.

All cases presented with isolated ZMC fractures in OPD assessed on radiographs as a breach in the continuity of bone, both gender (Male and Female) and Age $\geq 18$ to $\leq 70$ years. Patients with displaced zygomaticomaxillary complex fracture requiring Open Reduction and Internal Fixation (ORIF) based on radiographic and clinical assessment.

The exclusion criteria of this study is i.e comminuted zygomatic bone fracture, gunshot injuries, infected fractures, pathological fractures, Diabetic/Hypertensive patients and the patients who had medical comorbidities. These conditions are confounders, these created bias in study results if included. Medical emergency and any other procedure that may require immediate attention was dealt with first.

All the patients presented in OPD in Oral \& Maxillofacial Surgery Dept., with isolated ZMC fratures added according to the criteria of inclusion. All demographic details were collected. Bias and Confounders were controlled by exclusion criteria. All base line investigations were done for oral surgical procedure. Patients divided in groups i.e Group and Group B by lottery method and 37 patients in each. Group A was with one point fixation i.e. intraoral plate at zygomaticomaxillary buttress. Group B was with two point fixation i.e.one at zygomaticomaxillary and other at frontozygomatic buttress. Reduction of the fracture segments were assessed postoperatively by X-rays i.e. Occiptomental and Submentovertex views.

Patient was evaluated in terms of satisfaction of score on 3rd day, 14th day and 28th day and was recorded as per operational definitions.

For one point fixation, after giving general anesthesia under aseptic measures and standard surgical drapes, local anesthesia was given intraorally at ZM buttress area. Mucoperiosteal flap was elevated by making the incision of 1 to $2 \mathrm{~cm}$ at mucobuccal fold which extends to mucosa, submucosa and buccinators muscle fibres if present and fracture site was exposed. Closed Reduction was done initially and bony contour of zygoma was assessed. A five hole plate with $5 \mathrm{~mm} \times 2.5 \mathrm{~mm}$ screws on ZM buttress was fixed. Wound will be irrigated and was closed by 3:0 Vicryl suture. For two point fixation, after giving general anesthesia under aseptic measures and standard surgical drapes, in addition to the above mentioned procedure of fixation at ZM buttress and closed reduction, local anesthesia was given extraorally at FZ. A lateral blephroplasty or lateral eyebrow incision was given and flap was elevated to expose the fracture site at FZ. A four hole plate with $4 \mathrm{~mm} \times 2 \mathrm{~mm}$ screws on FZ was fixed. Wound was irrigated and closed by proline to minimize scar formation. Patient satisfaction was recorded by descriptive scale from 0 to 10 with 0 as 
Akram MH/ Ch MM/ Mirza AI/

Akhtar MU/ Saeed A

Pre-Operative Clinical Picture of the patient

Patient was presented with Left ZMC Fracture after RTA
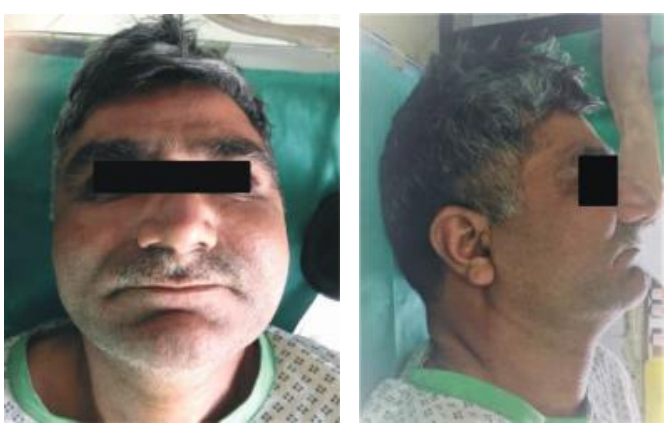

Frontal and Lateral Clinical Views

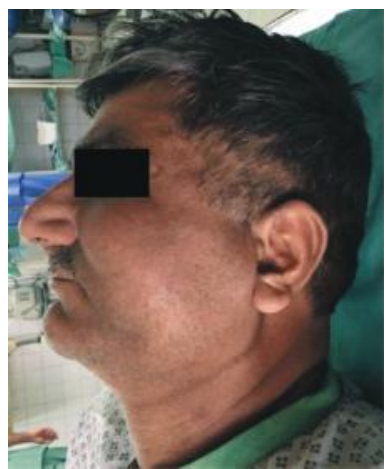

Intraoperative Clinical Pictures

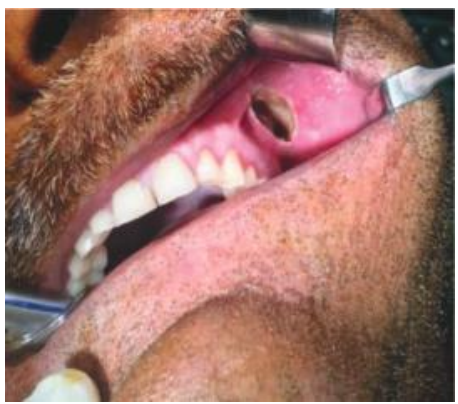

Incision at Left Buccal vestibule

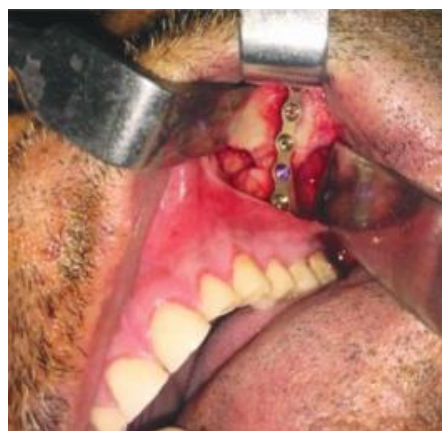

5 hole miniplate fixed at Buttress after reduction

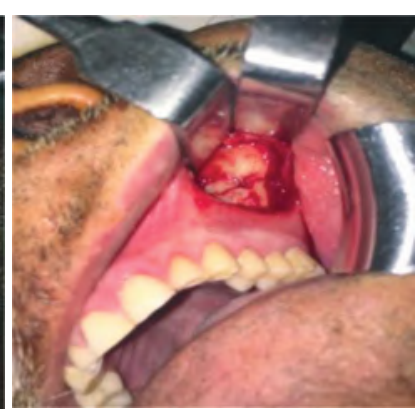

Flap Reflected to expose ZM Buttress

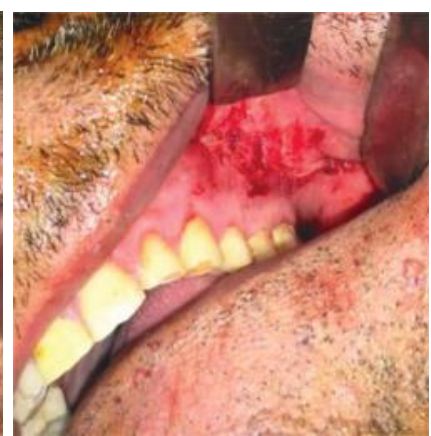

Incision closed by 3:0 Vicryl Suture
One point fixation versus two point fixation in zygomaticomaxillary complex fractures

Follow-up after 28 days(Extraoral)

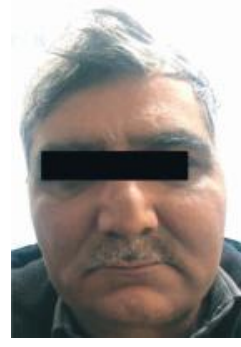

Frontal View

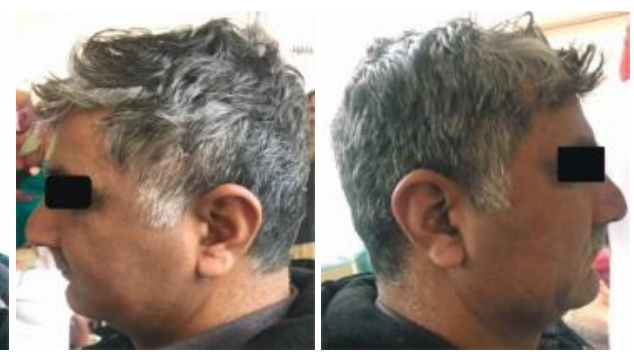

Lateral Views
Follow-up after 28 days(Intraoral)

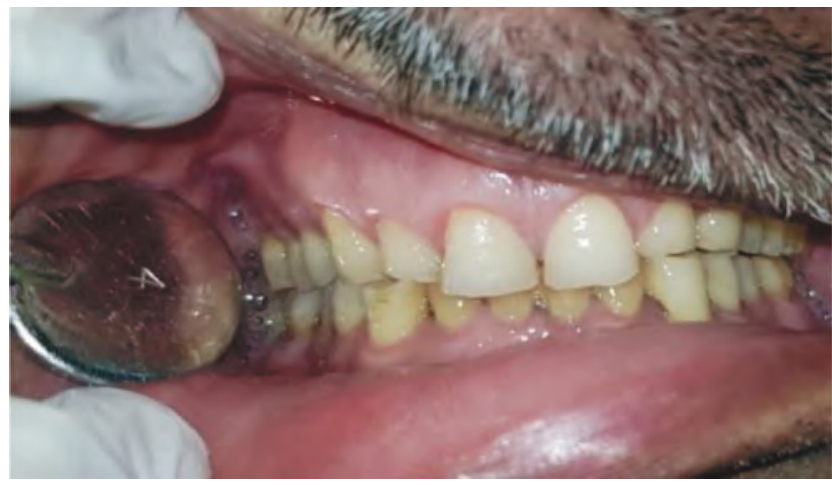

Occlusion

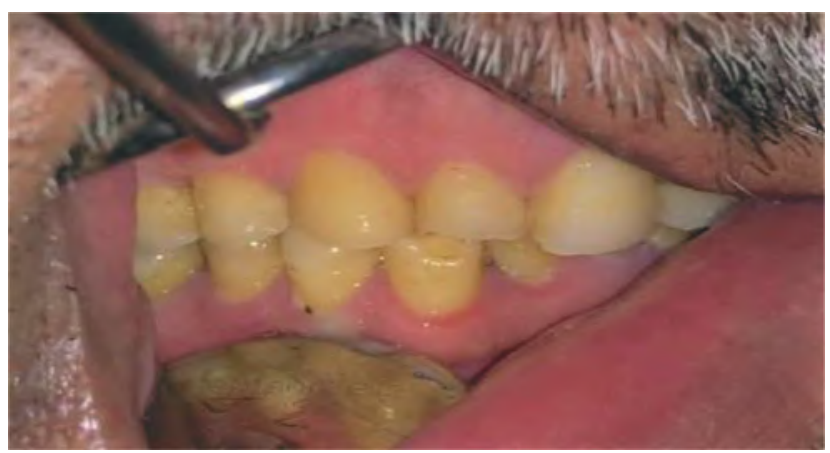

Right Side

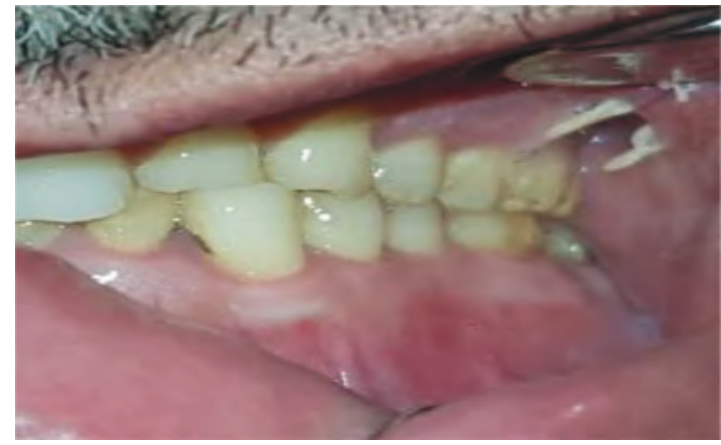

Left Side

Fig I: One point fixation-preoperative and postoperative assessment 
Akram MH/ Ch MM/ Mirza AI/

Akhtar MU/ Saeed A

Pre-Operative Clinical Picture of the patient Patient was presented with Right ZMC fracture after RTA

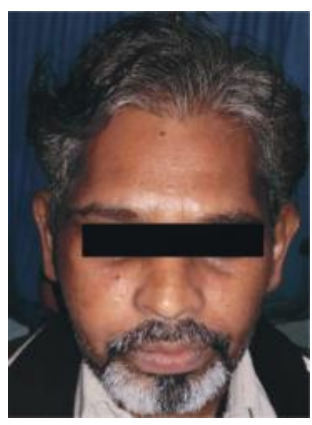

Frontal View

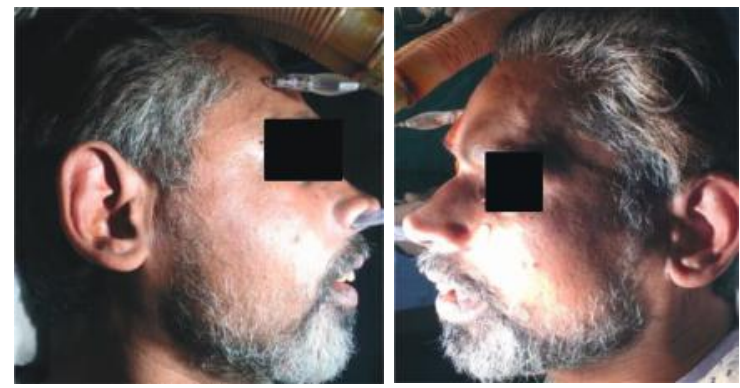

Lateral Views (Examination Under General Anaesthesia - EUA)

Intra-Operative Clinical Pictures

Gillie's Temporal approach fo Closed Reduction of Zygoma

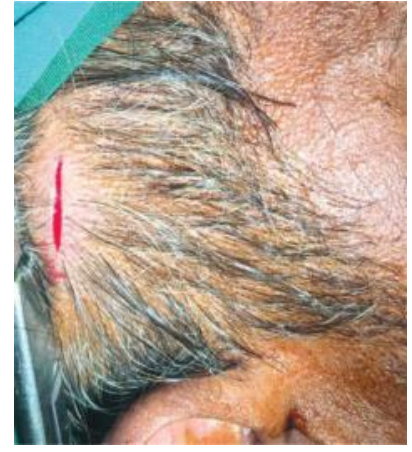

Incision is given at Right Temporal Line for indirect approach to zygoma
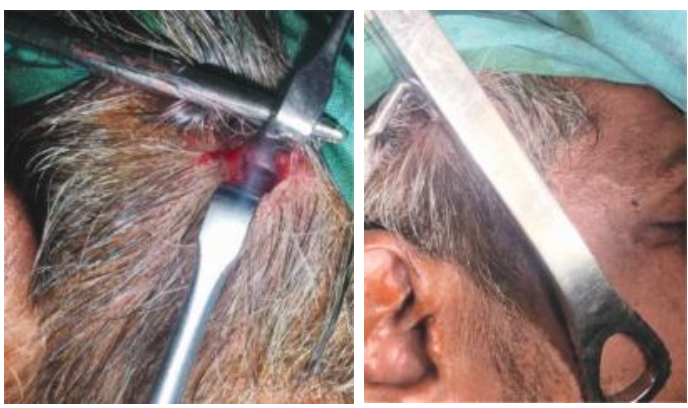

Fascial planes dissected till the muscle is exposed to insert Row's Elevator to reduce zygoma

One point fixation versus two point fixation in zygomaticomaxillary complex fractures

Intra-Operative Clinical Pictures

Lateral Blepharoplasty Skin Incision to expose FZ Suture

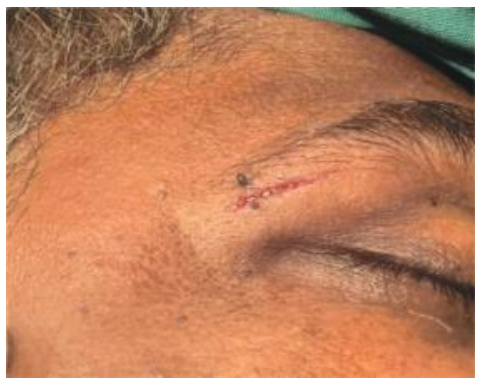

Skin Incision to expose FZ given

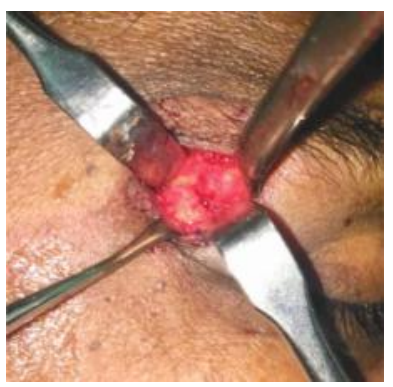

Flap reflected to

expose fracture line at FZ

Follow-up after 28 days(Extraoral)

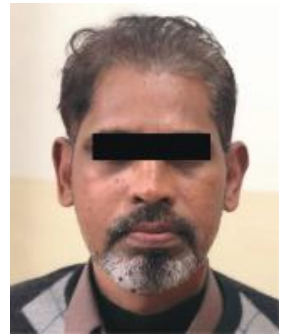

Frontal View

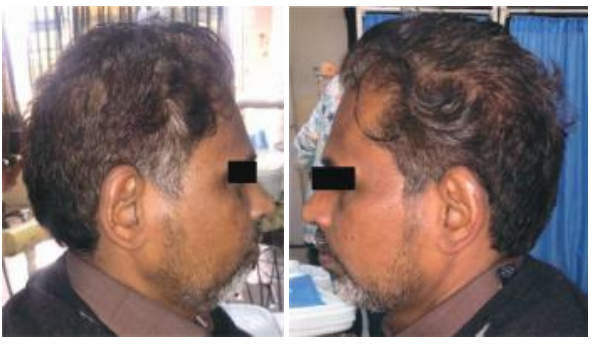

Lateral Views

Follow-up after 28 days(Intraoral)

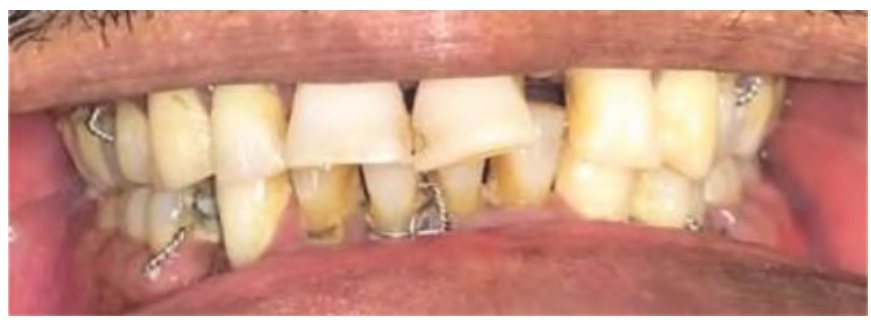

Occlusion after 28 days
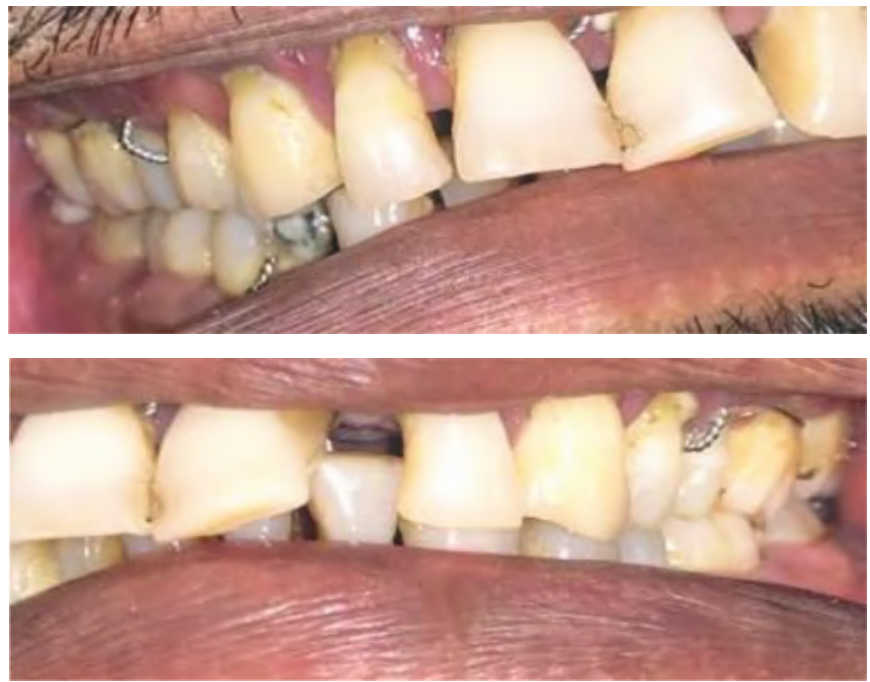

Fig II: Two point fixation-preoperative and postoperative assessment 
poor patient satisfaction and 10 as very satisfied patient on 3rd day, 14th and 28th post-operative day. The score was calculated in terms of mean of these readings.

The zygomatic bone has five main articulations and four processes. Previously published literature supported that at least two or three of these processes should be fixed (Two point versus three point fixation. There is sufficient literature evidence that suggests that adequate stability of fracture segments can be achieved with one point fixation (Ref. Kim ST, Go DH, Jung JH, Cha HE, Woo JH, Kang IG. Comparison of 1-point fixation with 2-point fixation in treating tripod fractures of the zygoma. Journal of Oral and Maxillofacial Surgery 2011;69(11):2848-52). Thus decreasing the surgical morbidity without any compromise. This in turn results in increased patient comfort and satisfaction. Hence we tested this technique with an established method just to assess patient satisfaction while making sure that adequate treatment has been provided.

\section{RESULTS}

All the data was entered and analysis was done on on SPSS 20.0. Continuous / Quantitative variables such as age of patient, pain score and patient satisfaction score were described in Mean \pm Standard Deviation. Categorical / Qualitative variables such as gender, infection at surgical site, were presented in the form of frequency and percentages. Effect modifiers such as age, gender, BMI was controlled through stratification Post stratification, T-test was applied by taking $\mathrm{p}=<0.05$ as significant. Comparison between these two was shown with the help of T-test. A "p" value of $\leq 0.05$ was considered to be significant.

The patients in terms of mean age in one point group was $42.46 \pm 15.325$ years while in two points group was $49.32 \pm 13.145$ years. There were $21(56.8 \%)$ males and 16 $(43.2 \%)$ females in one point group while there were 20 (54.1\%) males and 17 (45.9\%) females in two points group. The gunshot injuries and work related injuries were more common in both groups. Table 1

Table 1: Baseline characteristics of patients

\begin{tabular}{|l|l|c|c|}
\hline \multirow{2}{*}{ PSS at } & \multicolumn{2}{|c|}{ Study Groups } & P-value \\
\cline { 2 - 3 } & One point & Two points & \\
\hline $3^{\text {rd }}$ day & $3.59 \pm 1.09$ & $2.78 \pm 1.18$ & 0.003 \\
\hline $14^{\text {th }}$ day & $5.00 \pm 1.35$ & $3.49 \pm 1.10$ & $<0.001$ \\
\hline $28^{\text {th }}$ day & $7.00 \pm 1.97$ & $5.05 \pm 1.45$ & $<0.001$ \\
\hline Mean PSS & $5.20 \pm 0.89$ & $3.78 \pm 0.61$ & $<0.001$ \\
\hline
\end{tabular}

The mean PSS at 3rd day in one point group was $3.59 \pm 1.092$ while in two points group was $2.78 \pm 1.182$. This difference was statistically significant i.e. $p$-value $=0.003$. At 14th day in one point group was $5.00 \pm 1.35$ while in two points group was $3.49 \pm 1.096$. This difference was statistically

Table 2: Comparison of PSS in both groups

\begin{tabular}{|c|c|c|}
\hline \multirow{2}{*}{} & \multicolumn{2}{|c|}{ Study Groups } \\
\cline { 2 - 3 } & One point & Two points \\
\hline Age (years) & 37 & 37 \\
\hline Male & $\mathbf{4 2 . 4 6 \pm 1 5 . 3 3}$ & $49.32 \pm 13.15$ \\
\hline Female & $\mathbf{2 1 ( 5 6 . 8 \% )}$ & $\mathbf{2 0 ( 5 4 . 1 \% )}$ \\
\hline Etiology & & $17(45.9 \%)$ \\
\hline Road traffic accident & $\mathbf{6 ( 4 6 . 2 \% )}$ & $\mathbf{7 ( 5 3 . 8 \% )}$ \\
\hline Fall & $\mathbf{4 ( 4 4 . 4 \% )}$ & $\mathbf{5 ( 5 5 . 6 \% )}$ \\
\hline Interpersonal violence & $\mathbf{5 ( 4 1 . 7 \% )}$ & $\mathbf{7 ( 5 8 . 3 \% )}$ \\
\hline Sports accident & $\mathbf{5 ( 5 0 . 0 \% )}$ & $\mathbf{5 ( 5 0 . 0 \% )}$ \\
\hline Work accident & $\mathbf{9 ( 5 6 . 3 \% )}$ & $\mathbf{7 ( 4 3 . 8 \% )}$ \\
\hline Gunshot / blast injuries & $\mathbf{8 ( 5 7 . 1 \% )}$ & $\mathbf{6 ( 4 2 . 9 \% )}$ \\
\hline
\end{tabular}

significant i.e. $p$-value $<0.001$. At 28th day in one point group was $7.00 \pm 1.972$ while in two points group was $5.05 \pm 1.452$. This difference was statistically significant i.e. p-value $<0.001$. The mean PSS in one point group was $5.98 \pm 0.89$ while in two points group was $3.775 \pm 0.609$. This difference was statistically significant i.e. p-value $<0.001$ Table 2 .

\section{DISCUSSION}

Zygomatic complex fractures are one of the most common fractures of Facial skeleton. The prominence of zygoma give aesthetic look to the face and at the same time makes it vulnerable to get fractured.. About $45 \%$ of all midfacial fractures are zygomatic complex fractures. Several approaches are used namely lateral eyebrow, sub cilliary, temporal or intraoral incisions for these type of fractures ${ }^{8,9} \mathrm{In}$ this research, mean value of mean Patient satisfaction score in one point group was 5.98 \pm 0.89 while the mean value of mean Patients satisfaction score in two points group was 3.775 \pm 0.609 . Statistically one point fixation showed significantly better satisfaction score than to two point fixation i.e. $p$-value $=<0.001$. Some of the studies are discussed below showing their results as.

According to Seon Tae Kim et $\mathrm{al}^{2}$, the authors showed that we can avoid unsighty scars with better results and 
Akram MH/ Ch MM/ Mirza AI/ Akhtar MU/ Saeed A
One point fixation versus two point fixation in zygomaticomaxillary complex fractures outcome in one point fixation in selected patients .Many studies have demonstrated one point fixation sufficient in terms of stability and outcomes. ${ }^{10-13}$ Many different approaches and incision have been described and accepted by both patients and surgeons. ${ }^{14}$

According to Ritesh Vatsa et al, the treatment time in Group I patients was one hour and in Group II patients, two hours showing that one point fixation had shorter operating time. The author showed that one point fixation at zygomatic buttress is a viable option for minimally displaced ZMC fractures for comminuted zygomatic fractures, this one point fixation was not a feasible option.

According to Ji Heui Kim et $\mathrm{al}^{16}$, for non-comminuted ZMC fractures, fixaing the zygomaticomaxiilary buttres and avoiding the facial scar is a better option in all aspects. It was seen that for non-comminuted fractures, the one point fixation at zygomaticomaxillary buttress was stable confirming the studies of Fujioka et al. ${ }^{17}$ Sufficient alignment and rigidity can be achieved in one point if there is no comminution.

On the other hand Davidson et $\mathrm{al}^{18}$ who stated that one point fixation leads to unstability but two point fixation provides better stability than three point fixation.

\section{CONCLUSION}

This present study concluded that one point fixation is smarter method and provide significantly better satisfaction than to two point fixation method for ZMC fractures.

\section{CONFLICT OF INTEREST}

None to declare

\section{REFERENCES}

1. Rana M, Warraich R, Tahir S, Iqbal A, Von See C, Eckardt AM, et al. Surgical treatment of zygomatic bone fracture using two points fixation versus three point fixation-a randomised prospective clinical trial. Trials 2012;13:36:1-10.

https://doi.org/10.1186/1745-6215-13-36

2. Kim ST, Go DH, Jung JH, Cha HE, Woo JH, Kang IG. Comparison of 1-point fixation with 2-point fixation in treating tripod fractures of the zygoma. J Oral and Maxillofac Surg 2011;69:2848-52. https://doi.org/10.1016/j.joms.2011.02.073

3. Ogata H, Sakamoto Y, Kishi K. A new classification of zygomatic fracture featuring zygomaticofrontal suture: injury mechanism and a guide to treatment. Plastic Surg Int J 2013.

https://doi.org/10.5171/2013.383486

4. Arosarena OA, Fritsch TA, Hsueh Y, Aynehchi B, Haug R. Maxillofacial injuries and violence against women. Arch Faci Plastic
Surg 2009;11:48-52.

https://doi.org/10.1001/archfacial.2008.507

5. Chattopadhyay P, Chander M. Management of zygomatic complex fracture in armed forces. Med J Armed Forces India 2009;65:128-30. https://doi.org/10.1016/S0377-1237(09)80124-X

6. Chang C-M, Ko EC, Kao C-C, Chang P-Y, Chen MY. Incidence and clinical significance of zygomaticomaxillary complex fracture involving the temporomandibular joint with emphasis on trismus. The Kaohsiung J Med Sci 2012;28:336-40.

https://doi.org/10.1016/j.kjms.2011.11.016

7. PRIYA S, EBENEZERR V, Balakrishnan R. Versatility of Gillie's temporal approach in the management of ZMC fractures. Biomed Pharmacolog J 2014;7:253-6.

https://doi.org/10.13005/bpj/482

8. Manson PN, Crawley WA, Yaremchuk MJ, Rochman GM, Hoopes JE, French JJ. Midface fractures: advantages of immediate extended open reduction and bone grafting. Plastic Reconstruct Surg 1985;76: $1-12$.

https://doi.org/10.1097/00006534-198507000-00001

9. Dakir A, Muthumani T, Prabu N, Mohan R, Maity A. One point fixation of zygomatic tripod fractures in the zygomatic buttress through Keen's intraoral approach: A review of 30 cases. J Pharm Bioallied Sci 2015;7(Suppl 1):S238.

https://doi.org/10.4103/0975-7406.155934

10. Mavili ME, Canter HI, Tuncbilek G. Treatment of noncomminuted zygomatic fractures with percutaneous screw reduction and fixation. J Craniofacial Surg 2007; 18:67-73.

https://doi.org/10.1097/01.scs.00002467243.31106.81

11. Mohammadinezhad C. Evaluation of a single miniplate use in treatment of zygomatic bone fracture. J Craniofac Surg 2009;20:1398402.

https://doi.org/10.1097/SCS.0b013e3181acdc25

12. Shumrick KA, Kersten RC, Kulwin DR, Smith CP. Criteria for selective management of the orbital rim and floor in zygomatic complex and midface fractures. Archi Otolaryngolog-Head \& Neck Surg 1997; 123:378-84.

https://doi.org/10.1001/archotol.1997.01900040020003

13. Ellis E, Kittidumkerng W. Analysis of treatment for isolated zygomaticomaxillary complex fractures. J Oral Maxillofac Surg1996;54:386-400.

https://doi.org/10.1016/S0278-2391(96)90107-X

14. Kurita M, Okazaki M, Ozaki M, Tanaka Y, Tsuji N, Takushima A, et al. Patient satisfaction after open reduction and internal fixation of zygomatic bone fractures. J Craniofac Surg 2010;21:45-9. https://doi.org/10.1097/SCS.0b013e3181c36304

15. Vatsa R. Comparison of One Point Fixation Vs Two Point Fixation in the Treatment of Zygomatico Maxillary Complex Fractures. Int Healthcare Res J (IHRJ) 2018;2:229-34.

https://doi.org/10.26440/ihrj.v2i9.177 


Akram MH/ Ch MM/ Mirza AI/
Akhtar MU/ Saeed A

16. Kim JH, Lee JH, Hong SM, Park CH. The effectiveness of 1-point fixation for zygomaticomaxillary complex fractures. Archives of Otolaryngolog-Head \& Neck Surg 2012;138:828-32.

https://doi.org/10.1001/archoto.2012.1815

17. Fujioka M, Yamanoto T, Miyazato O, Nishimura G. Stability of one-plate fixation for zygomatic bone fracture. Plastic Reconstruct
One point fixation versus two point fixation in zygomaticomaxillary complex fractures

Surg 2002;109:817-8.

https://doi.org/10.1097/00006534-200202000-00069

18. Davidson J, Nickerson D, Nickerson B. Zygomatic fractures: comparison of methods of internal fixation. Plastic Reconstruct Surg 1990;86:25-32.

https://doi.org/10.1097/00006534-199007000-00004 